\title{
The Essence of Lean in Supply Chain
}

Vyas $\mathbf{N}^{*}$

Executive Director, Center for Global Supply Chain Management, USC Marshall School of Business, USA

Keywords: Supply chain; Globalization; Transportation

\section{Introduction}

Supply chain has been going through tremendous transformations on disruptive technologies and on micro and macro management trends. These changes are driving towards global trade. In order for supply chain companies to look out for potential changes they require a deal strategy. This strategy is essential to streamline the existing operations to become more efficient.

The impact of globalization has become imperative to streamline global supply chain management through a systematic approach of integration, innovation and identifying/reducing waste. Therefore a process of continuous improvement has enhanced the flow of products at the pull of the customer. This allows firms to pursue the art of perfection within a competitive supply chain environment. Simply put, doing it cheaper, better, faster without wasting any valuable resources produces effective results in the industry.

In terms of supply chain, Lean has proven to be an incredible tool for manufacturing industries. However, with time Lean has also been effective in other areas such as services and healthcare. One of the basic elements of Lean in supply chain is value- added analysis. The definition of value added analysis is the process that enhances a product or service to the market while identifying the customers who are willing to pay for that service.

How do we run a supply chain organization through a value -added analysis? In order to answer this question we need to understand how the wastes of Lean can be adapted into a supply chain framework.

\section{Wastes of Lean}

- Overproduction: Doing more, earlier or faster than the next operation needs it or is ready for it.

- Inventory: Having more than we need or not enough of what we need.

- Transportation: Moving items around including people.
- Under-utilized people: Not tapping into people's education, skills, experience, training, creativity, etc.

- Over-processing: Doing more than the customer asks for and would not be willing to pay for it.

\section{Defects}

Errors in forecasting, batch size, network model, reverse logistics and broken promises. Value analysis needs to be looked through the lenses of a customer; in some cases it can either be an end customer or an internal customer. Many organizations assume that they are creating value through various value added processes. However, in many instances they fail to relate to customers who are willing to paying for it, or identify which of their services are differentiating their capabilities in a market place. If the organization's value added process is not enhancing their value added service, nor is the customer willing to pay for that service, we consider this outcome to be nonvalue ads. This is something organizations need to continue to look to eliminate. Non-value added processes are essential where firms are both internally or externally required to execute services that are mandated by regulatory compliances. Often in supply chain firms these practices are not challenged. This is due to the assumption that if the majority of companies follow the same path the rest of the industry must continue to do so. Therefore organizations need to identify these steps and understand which regulations are required to validate the non-value added practices.

If organizations fail to validate these practices they should eliminate those particular services. However if companies are successful they should automate their services and make it more efficient.

Through this process, supply chain can continue to evolve and be streamlined to become value add propositions for organizations. It is vital for supply chain firms to focus on these disruptive forces and evolutions but continue to carry out their core services efficiently.

The approach of streamlining the current process and managing future outcomes will create a unique opportunity for future supply chain organizations to become value added companies. 